\title{
OCEANIC INFLUENCES ON THE ANGULAR VELOCITY OF THE EARTH
}

\author{
P. BRosCHE \\ Observatorium Hoher List \\ Univ. Sternwarte Bonn \\ D-5568 Daun \\ Germany, Fed.Rep.
}

ABSTRACT. Hydrodynamical computations of the major partial tides in the oceans have been evaluated for the changes both in moment of inertia and relative angular momentum due to ocean currents. If the system solid Earth plus oceans is seen as an isolated system for these time scales, the oceanic variations lead to mirror-like changes in the rotation of the solid Earth. Amplitudes are of the order of $0.1 \mathrm{~ms}$ in Universal time. In contrast to the effects of solid Earth tide, phases are away from equilibrium phases.

\section{THE PROGRAM COMPLEX “KIEV — GEODYNAMIC R1”}

\author{
M.M. MEDVEDSKY \\ Main Astronomical Observatory \\ Ukrainian Academy of Sciences \\ 252127 Kiev, USSR
}

ABSTRACT. The software for the reduction of the VLBI observations of the Main Astronomical Observatory of the Ukrainian Academy of Science is described.

Our program complex has three parts:

1) calculation of geometrical delay $\tau$.

2) calculation of required corrections to values of $\tau$.

3) data analysis procedures.

This software has been tested using the NGS VLBI data for the obtaining of corrections to the ERP. The parameters of the clock were derived. Our results were compared with similar results, which were published by Shanghai observatory (China) and IRIS bulletin.

The differences between our results and the data given in the IRIS bulletin are within 5 mas, and for UT are within $0.1 \mathrm{~ms}$.

\section{CURRENT STATE OF THE THEORY OF NUTATION}

\section{S.M. MolodensKIJ}

O.Yu. Shmidt Institute for Earth Physics

Bol. Gruzinskaya 10

123810 Moscow D-242, USSR

Paper not available. 